\title{
Attacking 'prejudice' against generics could save SA billions
}

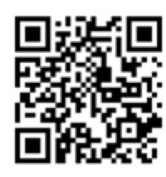

The use of generics in South Africa (SA) is growing in line with trends in the UK and the USA - but is still nowhere near their levels.

Local overall healthcare spend could be reduced by ZAR4 billion should users take advantage of the newer generics on the market.

With SA healthcare costs off the charts generally for brutally argued reasons (which the Competitions Commission enquiry will recommend on within months), this kind of saving is a no-brainer - but will require a major shift in perceptions on the part of both doctors and their patients.

This is according to Vivian Frittelli, CEO of the National Association of Pharma- ceutical Manufacturers (NAPM, which represents the interests of generic medicine manufacturers and marketers in SA and the mission of which is to champion greater access to medicine for the SA population), and the first SA President of the International Generic Pharmaceutical Alliance. He told Izindaba that generics were often wrongly perceived by both doctors and patients to be inferior because they were cheaper. Sophisticated marketing by originator drug companies reinforced this message.

'I worked for an originator company for 20-odd years and one of our messages was this: if your kid had meningitis, would you use generics? It's the fear factor, and prejudices many doctors against generics which the patient obviously follows.'
Frittelli said the ZAR4 billion saving was based on $18 \%$ of originator drugs having come off patent, allowing generic drugs to fill the gap and therefore be available for the taking. However, use nowhere near matched this because of die-hard traditional consumer behaviour patterns.

A recent NAPM study comparing the cheapest generics $\mathrm{v}$. originator drug prices found that the difference in price of the 200 most prescribed medicines in the private sector had risen to a whopping $56.1 \%$ in favour of generics. Explains Frittelli: 'In other words, basket for basket, you'd save $56.1 \%$ by using generics.' Since 2010 there had been a steady increase in the cost advantage of generics over originator drugs. Considering that production standards 
and manufacturing costs for both original and generic medicines were similar, these findings were 'highly significant', says Frittelli. According to IMS Health, a global organisation that tracks data at sales level, generics account for about $65 \%$ of all items dispensed in SA's private sector, yet cost only $40 \%$ of the ZAR22 billion expenditure on drugs.

Using claims data from more than 1 million medical aid members, Mediscor, a pharmacy benefit management organisation, puts generic use at 56\%, and growing. Based on data gleaned from IMS Health, every $1 \%$ increase in the use of generics would save consumers around R270 million. 'These savings would enable medical schemes to offer improved benefits or to curb increases in premiums to their members. They also provide a direct benefit for consumers paying for medicines out of pocket or through their medical scheme savings accounts,' adds Frittelli.

\section{Discovery backs NAPM findings}

Discovery Health's publication Medicine Summit Journal 2015, using data from medical aids administered by Discovery, supports the NAPM findings, reporting a $58.8 \%$ utilisation of generics by volume and $46.6 \%$ by value. The Discovery summit also revealed that $65 \%$ of generic medicines are priced at $40 \%$ below their originator equivalents, while at least $48 \%$ of generics are priced at $50 \%$ or more below their originator equivalents. In practical terms, for a patient with asthma and allergic rhinitis, complicated once by a fungal infection in the throat due to inhaler use, the savings over a year could be nearly ZAR4 000 should generics

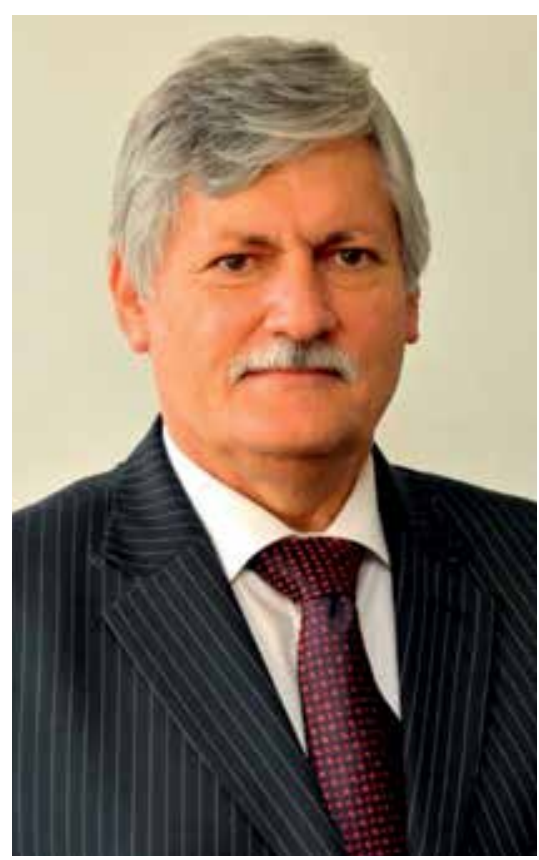

Mr Vivian Frittelli, CEO of the National Association of Pharmaceutical Manufacturers and the first South African President of the International Generic Pharmaceutical Alliance. be used. The trend in SA follows that in the UK, where more than two-thirds of all medicines dispensed by the National Health Service (NHS) are generics yet cost only around $29 \%$ of the NHS drugs bill, and the USA, where nearly eight out of ten prescriptions filled are for generics, causing expenditure on drugs to slow despite an increase in the price of prescription drugs.

\section{'I worked for an originator} company for 20-odd years and one of our messages was this: if your kid had meningitis, would you use generics? It's the fear factor, and prejudices many doctors against generics - which the patient obviously follows.

'As life expectancy increases and the cost of medicines escalates, the importance of the generics industry is being highlighted as it allows more people greater access to healthcare. The value proposition presented by generics cannot be disputed,' Frittelli said.

\section{Chris Bateman}

chrisb@hmpg.co.za

S Afr Med J 2015;105(12):1004-1005. DOI:10.7196/SAMJ.2015.v105i12.10317 